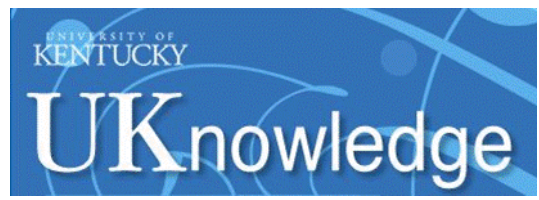

University of Kentucky

UKnowledge

Biosystems and Agricultural Engineering Faculty Publications

2018

\title{
Validating Spray Coverage Rate Using Liquid Mass on a Spray Card
}

\author{
Michael P. Sama \\ University of Kentucky, michael.sama@uky.edu
}

Austin M. Weiss

University of Kentucky, austin.weiss@uky.edu

Emma K. Benedict

University of Kentucky

Follow this and additional works at: https://uknowledge.uky.edu/bae_facpub

Part of the Bioresource and Agricultural Engineering Commons

Right click to open a feedback form in a new tab to let us know how this document benefits you.

\section{Repository Citation}

Sama, Michael P.; Weiss, Austin M.; and Benedict, Emma K., "Validating Spray Coverage Rate Using Liquid Mass on a Spray Card" (2018). Biosystems and Agricultural Engineering Faculty Publications. 219.

https://uknowledge.uky.edu/bae_facpub/219

This Article is brought to you for free and open access by the Biosystems and Agricultural Engineering at UKnowledge. It has been accepted for inclusion in Biosystems and Agricultural Engineering Faculty Publications by an authorized administrator of UKnowledge. For more information, please contact UKnowledge@lsv.uky.edu. 


\section{Validating Spray Coverage Rate Using Liquid Mass on a Spray Card}

\section{Digital Object Identifier (DOI)}

https://doi.org/10.13031/trans.12565

\section{Notes/Citation Information}

Published in Transactions of the ASABE, v. 61, issue 3, p. 887-895.

(C) 2018 American Society of Agricultural and Biological Engineers

The copyright holder has granted the permission for posting the article here. 


\title{
VALIDATING SPRAY COVERAGE RATE USING LIQUID MASS ON A SPRAY CARD
}

\author{
M. P. Sama, A. M. Weiss, E. K. Benedict
}

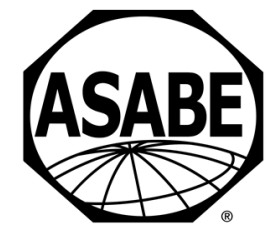

\begin{abstract}
Validation of agricultural sprayers is important for quantifying as-applied coverage rates under field conditions. The complexity of modern sprayer control systems presents a challenge for precise field validation due to the use of nozzle control technologies, such as pulse width modulation, to meter chemical flow rates at individual nozzles. Non-uniform flow over time may result in local variations at high spatial resolutions that are ignored when estimating as-applied coverage rates across a field. The purpose of this study was to test several methods for estimating the mass of water applied to a water-sensitive paper spray card target using steady-state and instantaneous measurement techniques. The steady-state method consisted of a spray patternator table used to quantify the mass flow rate distribution across the nozzle width at varying nozzle pressures. The mass flow rate was then projected onto a two-dimensional area traveling across the spray width to calculate the mass of water that was deposited in the area. Two instantaneous sampling methods were used. The first method directly measured the mass of the spray card and water for 5 min after exposure to model the evaporation rate and solve for the initial mass at the time of exposure. The second method indirectly used the percent coverage of the exposed spray card by droplets. Results showed that the error between the calculated mass of water from the mass flow rate and the estimated initial mass of water from the evaporation rate varied between $2 \%$ and $8 \%$. The relationships between the calculated and estimated initial mass of water methods and the spray card percent coverage were highly linear $\left(R^{2}>0.98\right)$. Both instantaneous methods produced results with higher variability between replications than the steady-state method, but the number of replications resulted in acceptably small differences between average mass measurements. These results show the potential for using evaporation rates for laboratory validation and percent coverage for laboratory or field validation of as-applied coverage rates.
\end{abstract}

Keywords. Evaporation rate, Flow measurement, Precision agriculture, Sprayers, Water-sensitive paper.

A dvanced sprayer systems used for precision management of crops can generate as-applied maps that spatially estimate application rates based upon sprayer movement and settings. However, the processes used to create as-applied maps do not consider local variations in environmental conditions (e.g., wind) or banding due to pulse width modulation (PWM) control. Rather, they are a theoretical representation of as-applied application based on ideal conditions and assumptions. Mangus et al. (2017) showed through simulation that as-applied application error varied with PWM duty cycle and commonly exceeded $\pm 10 \%$ of the target rate. The steady-state flow rate distributions for various nozzle settings were measured using a spray patternator table and the as-applied rate projected to a surface based on instantaneous nozzle settings. Luck et al. (2016) previously found the error in flow distribution measurements using this method to be negligible, which in-

Submitted for review in August 2017 as manuscript number MS 12565; approved for publication by the Machinery Systems Community of ASABE in March 2017.

The authors are Michael P. Sama, Assistant Professor, Austin M. Weiss, Graduate Research Assistant, and Emma K. Benedict, Undergraduate Research Assistant, Department of Biosystems and Agricultural Engineering, University of Kentucky, Lexington, Kentucky. Corresponding author: Michael P. Sama, 119 C.E. Barnhart Building, University of Kentucky, Lexington, KY 40546; phone: 859-218-4325; e-mail: michael.sama@uky.edu. dicated that the nozzle flow patterns at varying pressures were suitable for simulating as-applied applications. Methods for quantifying as-applied application in laboratory and field studies are crucial for validating and further developing spray application simulation models.

The spatial resolution at which error is quantified is a crucial parameter for discerning application rate errors. In the Mangus et al. (2017) study, the average flow rate of chemical leaving the nozzle was shown to be correct, but the high spatial resolution of the simulated spray coverage revealed areas with off-rate applications. A lower spatial resolution analysis would have averaged the spatial variability and concluded that the correct amount of chemical had been applied over the entire extent. One option for optimizing spatial resolution is to use vector-based calculations of as-applied application rates. Luck et al. (2011) used polygons defined by boom width and velocity, as determined by GPS coordinates, to estimate off-rate errors due to turning movements. The resulting assessment was computed at a resolution that was spatially matched to the data collection method.

Validation of chemical applications is an important process for accurately and precisely quantifying agricultural inputs. Field validation methods have primarily focused on spray coverage using targets. Water-sensitive paper (WSP) spray cards used to capture spray depositions are capable of quantifying coverage rates and droplet diameters (Turner and Huntington, 1970). Numerous studies have used WSP 
spray cards to analyze as-applied spray coverages in ground applications (Giles and Downey, 2003; Womac et al., 2001) and aerial applications (Hill and Inaba, 1989), with much of the work focusing on spray card scanning and analysis (Fox et al., 2003; Zhu et al., 2011). Sama et al. (2016) extended prior WPS spray card work by demonstrating that spray coverage rates on WSP spray cards could be used to quantify the total volumetric flow rate from a series of flat-pattern spray nozzles. A key limitation of flow estimation using WSP spray card coverage is the saturation effect that occurs at high coverage rates. Material costs and processing time are also issues when scaling experiments over large areas, or when quantifying variable coverages at high spatial resolutions (e.g., PWM-controlled nozzles). Furthermore, measuring the flow rate before the nozzle using a flowmeter or estimating the flow rate based on nozzle pressure is less complex and does not require knowledge of the boom height or velocity to maintain accuracy. Other methods involve the use of resistive spray deposition sensors (Crowe et al., 2005; Kesterson et al., 2015; Salyani and Serdynski, 1990) to estimate spray coverage over a target area.

While individual nozzle flow rates are useful for assessing sprayer control performance, localized as-applied application rates are ultimately needed to compare prescriptions with actual dosages at the individual plant level. Techniques are needed to validate liquid flow rates at high spatial and temporal resolutions under actual field conditions. One possible direction is to incorporate computational fluid dynamics and appropriate sources of environmental and sprayer performance data to more accurately model as-applied rates. However, this is an unrealistic approach outside of research due to the scale of production agricultural practices. Therefore, a simpler method using WSP spray cards is proposed and demonstrated in this article. The overall objective of this study was to determine if the evaporation of liquid water on a spray card and/or the percent coverage on the spray card can be used to estimate the initial mass of water applied to the spray card. Specific objectives were as follows:

1. Calculate the expected liquid mass on a spray card from the steady-state mass flow distribution of a nozzle using a spray patternator table.

2. Estimate the initial liquid mass on a spray card by modeling the evaporation rate after exposure.

3. Compare spray card coverage to liquid mass estimates.

\section{MATERIALS AND METHODS}

Seven nozzle models (TP800xEVS Visi-Flo Even Flat Spray Tips, TeeJet Technologies, Wheaton, Ill.) with a flat $80^{\circ}$ uniform pattern were tested with ten replications per nozzle for a total of 70 samples. All tests were conducted at a manufacturer-recommended nozzle height of $76 \mathrm{~cm}$ (30 in.) and a nominal pressure of $345 \mathrm{kPa}$ (50 psi) supplied by a helical gear pump and piston-type pressure regulating valve. A solenoid valve was held in the on position to enable nozzle flow during testing. A pressure sensor located immediately upstream of the nozzle was used to quantify nozzle pressure. Additional details on the liquid flow components used in this study can be found in Sama et al. (2016). WSP spray cards (52 $\mathrm{mm} \times 76 \mathrm{~mm}$, Syngenta, Basel, Switzerland) were used to capture spray deposition for evaporation rate and coverage measurements. Tests were conducted in a conditioned laboratory with nominal temperature and relative humidity of $72^{\circ} \mathrm{C}$ and $50 \%$, respectively. The water used in this study was stored in a $375 \mathrm{~L}$ (100 gal) tank. The water temperature was not recorded and was assumed to be near ambient air temperature due to the large storage volume and short durations of use. Spray cards were allowed to fully dry under ambient conditions before being digitized on a flatbed scanner (V600, Epson America, Long Beach, Cal.) within $48 \mathrm{~h}$ of initial exposure, which limited self-exposure due to ambient moisture in the air.

\section{CAlCulating Liquid Mass on Spray CARds With STEADY-STATE MASS Flow Distributions From Nozzles Using a SPRAY PatTernator Table}

The volumetric flow rate distribution for the nozzles used in this study were previously quantified by Sama et al. (2016) on a spray patternator table. The nozzles were mounted $76 \mathrm{~cm}$ (30 in.) above the surface of the spray patternator table. The data used from that study were collected at five pressures between 207 and $483 \mathrm{kPa}$ (30 to $70 \mathrm{psi}$ ) under steady-state conditions. Volumetric flow rate per unit distance was computed by averaging measurements \pm 3 flow channels from the center of the nozzle, which represented the approximate region under the spray pattern where the spray card target would be present during subsequent testing. Mass flow rate per unit distance was determined by assuming the density of water was $1 \mathrm{~g} \mathrm{~mL}^{-1}$ (eq. 1):

$$
\dot{m}_{d}=\dot{q}_{d} \frac{1000}{60}
$$

where

$\dot{m}_{d}=$ mass flow rate per unit distance $\left(\mathrm{mg} \mathrm{s}^{-1} \mathrm{~cm}^{-1}\right)$

$\dot{q}_{d}=$ volumetric flow rate per unit distance $\left(\mathrm{mL} \mathrm{min}^{-1}\right.$ $\mathrm{cm}^{-1}$ )

$1000=$ density of water in milligrams per $\mathrm{mL}\left(\mathrm{mg} \mathrm{mL}^{-1}\right)$ $60=$ number of seconds per minute $\left(\mathrm{s} \mathrm{min}^{-1}\right)$.

A linear function describing the mass flow rate per unit distance versus nozzle pressure was determined from the experimental data using least-squares regression for each nozzle. This allowed mass flow rate per unit distance to be computed at any nozzle pressure over the range of pressures tested and to use the instantaneous nozzle pressure during testing rather than the nominal pressure setting. The mass of water on the spray card was then determined using the geometry of the spray card and the velocity under the spray nozzle. The spray card dimensions were nominally $5.1 \times$ $7.6 \mathrm{~cm}(2 \times 3 \mathrm{in}$.), with a portion of the bottom edge covered by a clamp that held the card in place on the test fixture. The actual average sampling dimensions were measured to be $5.03 \times 6.77 \mathrm{~cm}$. The spray cards were individually translated $76 \mathrm{~cm}$ underneath and $5 \mathrm{~cm}$ offset from the center of the spray nozzle using a rotary test fixture at a nominal angular velocity $3.14 \mathrm{rad} \mathrm{s}^{-1}$ and a radius of $118 \mathrm{~cm}$ (fig. 1).

Control and performance characteristics of the rotary test 


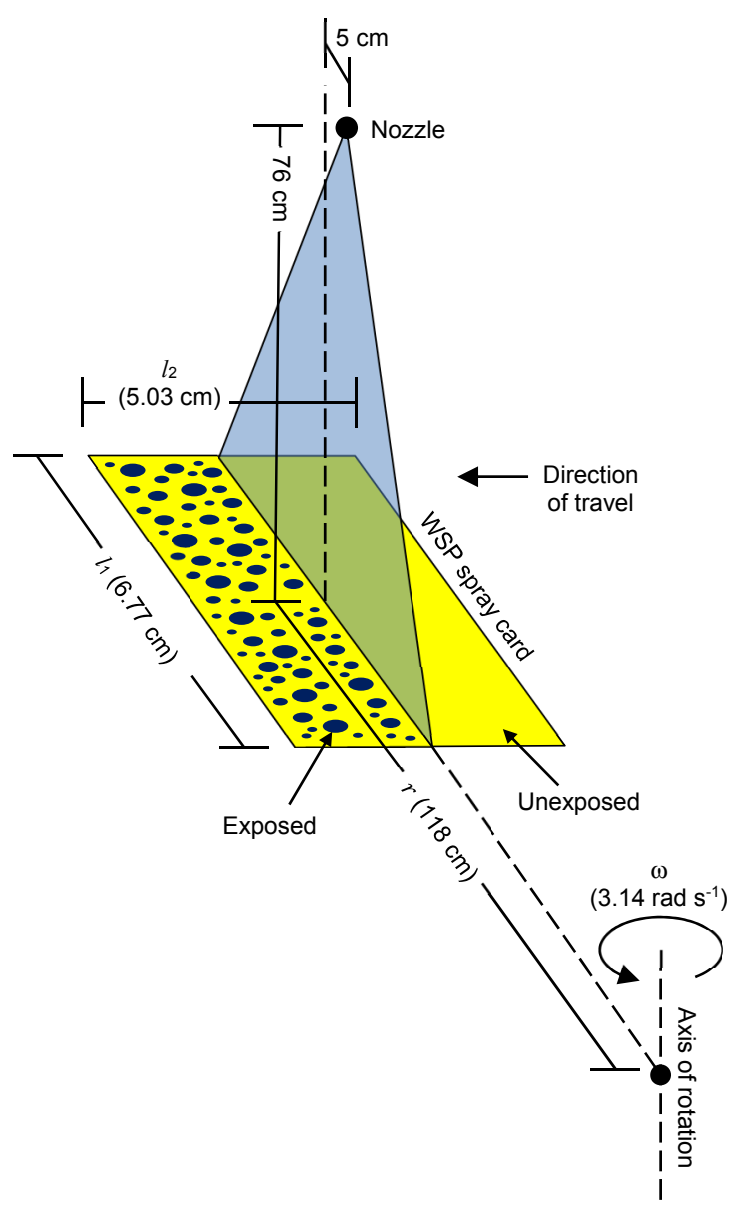

Figure 1. Physical layout of spray card traveling through the nozzle spray pattern. Dimensions are not to scale, and actual spray pattern width exceeded the spray card length.

fixture were previously described by Sama et al. (2016). In summary, the solenoid valve was turned on, and nozzle flow was allowed to reach steady-state flow before the spray card was accelerated to a constant angular velocity. After spray card exposure, the valve was turned off, and the spray card decelerated until stopping at one full revolution. The longer dimension $\left(l_{1}\right)$ of the spray card was aligned parallel with the width of the spray nozzle output. Speed variation across the longer dimension while passing underneath the nozzle along an arc was ignored, resulting in a nominal linear velocity of $371 \mathrm{~cm} \mathrm{~s}^{-1}$ (eq. 2):

$$
v=\omega \times r
$$

where

$v=$ spray card linear velocity $\left(\mathrm{cm} \mathrm{s}^{-1}\right)$

$\omega=$ spray card angular velocity $\left(\mathrm{rad} \mathrm{s}^{-1}\right)$

$r=$ rotary test fixture radius $(\mathrm{cm})$.

Linear velocity and the shorter spray card dimension $\left(l_{2}\right)$ were used to determine the spray card duration of exposure underneath the nozzle (eq. 3). The nominal duration of exposure was $13 \mathrm{~ms}$ :

$$
t_{\text {exp }}=l_{2} / v
$$

where

$t_{\text {exp }}=$ spray card exposure duration (s) $l_{2}=$ spray card width $(\mathrm{cm})$.

The mass of water on the spray card was calculated by computing the product of the mass flow rate per unit distance, the spray card length, and the exposure time (eq. 4). The average mass flow rate per unit distance of $\pm 7.6 \mathrm{~cm}( \pm 3$ flow channels) from the center of the nozzle, which represented the region in which the spray card was translated through the spray pattern, was used to represent a constant mass flow rate per unit distance across the entire card length $\left(l_{1}\right)$ :

$$
m=\dot{m}_{d} \times l_{1} \times t_{\text {exp }}
$$

where $m$ is the calculated mass of water on the spray card using steady-state mass flow distribution (mg).

The actual angular velocity of the rotary test fixture and the nozzle operating pressure at the spray card exposure time were measured using the optical encoder $\left(0.0006 \mathrm{rad} \mathrm{s}^{-1}\right.$ resolution) and pressure sensor ( $0.2 \mathrm{kPa}$ resolution) described by Sama et al. (2016), and the pressure sensor was re-calibrated prior to the experiment using a digital pressure gauge (700G27, Fluke Corp., Everett, Wash.). Therefore, small deviations in actual exposure time and nozzle pressure were accounted for when calculating the mass of water deposited on each spray card.

\section{ESTIMATING INITIAL LIQUID MASS ON SPRAY CARDS BY MODELING EVAPORATION RATE AFTER EXPOSURE}

The mass of each unexposed spray card was determined using an analytical balance (PA224C, Ohaus Corp., Parsippany, N.J.) with a readability of $0.1 \mathrm{mg}$. The average initial mass of the spray cards was $0.766 \mathrm{~g}$ with a standard deviation of $0.005 \mathrm{~g}$. Immediately after exposure, the mass of the spray card and water were recorded in $1 \mathrm{~s}$ intervals for $5 \mathrm{~min}$ using a PC connected to the RS-232 serial interface on the balance. The resulting change in mass followed an exponential decay as the water on the spray card evaporated. Figure 2 shows the typical mass response due to evaporation. The stabilization time for the analytical balance was specified to be $3 \mathrm{~s}$, and there tended to be discontinuities immediately after

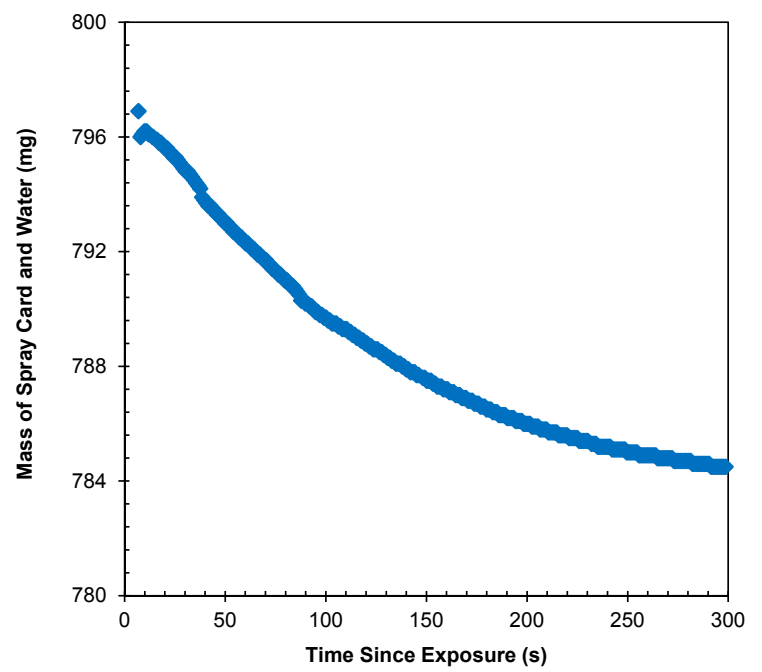

Figure 2. Change in mass of water on spray card due to evaporation. 
the exposed spray card was placed on the scale. Therefore, the first several seconds of mass measurements were removed to prevent the scale response time from influencing the evaporation rate model. The default method for removing data during stabilization was to find the last peak and remove all measurements beforehand. A second method of removing all points up to an arbitrary time after exposure was also evaluated to determine how quickly the spray card needed to be placed on the scale before the evaporation model predicted a significantly different initial mass as compared to the mass flow method.

The mass of the spray card was subtracted from the mass data time series, and a first-order step function response was used to model the resulting dataset in the time-domain. The model had three parameters that controlled the initial value $(a+c)$, decay rate $(b)$, and final value (c) (eq. 5):

$$
\hat{m}(t)=a \times e^{-b t}+c
$$

where

$$
\begin{aligned}
& \hat{m}(t)=\text { mass function (mg) } \\
& t=\text { time since exposure (s) } \\
& a, b, c=\text { model coefficients. }
\end{aligned}
$$

The fit function in the curve fitting toolbox of MATLAB (R2017a, The MathWorks, Natick, Mass.) was used to numerically solve the model parameters for each sample. Modeling each sample, rather than by nozzle type, accounted for small variations in droplet spectra and ambient conditions that resulted in varying evaporation rates. The initial mass of water at exposure was predicted by solving the modeled mass equation at time zero $(\hat{m}(0))$. Statistical t-tests $(\alpha=$ $0.05)$ were used to test the null hypothesis that the average calculated mass of water from the mass flow rate and the average estimated initial mass of water from the evaporation rate for each nozzle were equal.

\section{COMPARING SPRAY CARD COVERAGE \\ TO LIQUID MASS ESTIMATES}

After the mass data were collected for modeling the evaporation rates, each spray card was labeled on the bottom portion of the card. The label consisted of the nozzle model followed by the nominal operating pressure (in psi) and the replication number. The spray cards were then scanned at $4800 \times$ 4800 dpi resolution and processed for percent coverage. The process involved using a MATLAB script to remove the borders and label, distinguish droplets from the background, and compute the percent coverage as a ratio of the number of pixels containing a droplet over the total number of pixels and was identical to the process described by Sama et al. (2016). Spray card percent coverage was compared to the calculated mass of water from the mass flow rate and estimated initial mass of water from the evaporation rate to determine if a linear relationship existed using regression analysis.

\section{RESULTS AND DISCUSSION \\ Calculating Liquid Mass on Spray Cards With Steady-STATE MASS Flow Distributions From Nozzles Using a SPRAY PATternator TABLE}

Steady-state analysis revealed a linear relationship between nozzle pressure and mass flow rate per unit distance. The mass flow rate per unit distance was higher for larger orifices at a given pressure, and the slope between mass flow rate per unit distance and nozzle pressure increased with orifice size (fig. 3).

The slope, intercept, and coefficient of determination for the linear regression of each nozzle tested are shown in table 1 . The slope and intercept values allowed the mass flow rate per unit distance to be calculated for any pressure over the range tested. Note that the linear regression equation predicts a non-zero mass flow rate per unit distance when the

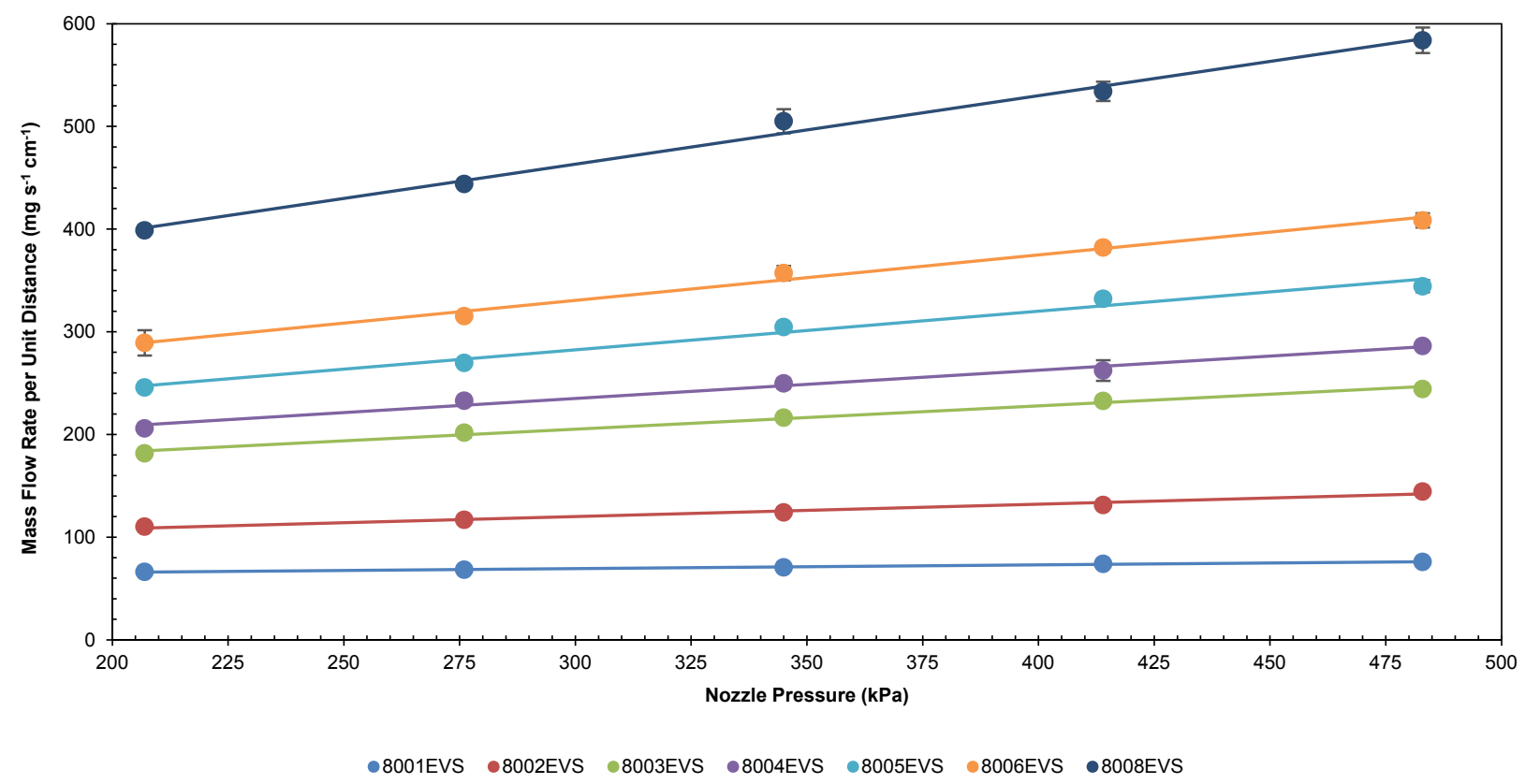

Figure 3. Mass flow rate per unit distance versus nozzle pressure for seven different nozzles in a series. Each data point represents the average of three replications at the same nozzle pressure, and error bars represent \pm 1 standard deviation in mass flow rate per unit distance. 
Table 1. Linear regression parameters for calculating mass flow rate per unit distance from nozzle pressure.

\begin{tabular}{cccc}
\hline $\begin{array}{c}\text { Nozzle } \\
\text { Model }\end{array}$ & $\begin{array}{c}\text { Slope } \\
\left(\mathrm{mg} \mathrm{s}^{-1} \mathrm{~cm}^{-1} \mathrm{kPa}^{-1}\right)\end{array}$ & $\begin{array}{c}\text { Intercept } \\
\left(\mathrm{mg} \mathrm{s}^{-1} \mathrm{~cm}^{-1}\right)\end{array}$ & $\mathrm{R}^{2}$ \\
\hline 8001EVS & 0.036 & 58.5 & 0.992 \\
8002EVS & 0.120 & 84.0 & 0.980 \\
8003EVS & 0.227 & 137 & 0.992 \\
8004EVS & 0.276 & 152 & 0.985 \\
8005EVS & 0.376 & 170 & 0.980 \\
8006EVS & 0.443 & 198 & 0.992 \\
8008EVS & 0.667 & 263 & 0.991 \\
\hline
\end{tabular}

nozzle pressure is zero. Therefore, the equation should not be used for extrapolating mass flow rate per unit distance outside of the nozzle pressures tested.

\section{ESTIMATING INITIAL LIQUID MASS ON SPRAY CARDS BY MODELING EVAPORATION RATE AFTER EXPOSURE}

Removal of data before scale stabilization produced an exponential decay of mass as a function of time. Consistency between the steady-state mass calculation and the estimated initial mass from the evaporation rate was exhibited by the exponential model intersecting the calculated mass from the mass flow rate method. Figure 4 shows which data points were removed during balance stabilization and provides an example of good and poor alignment between the two methods. The estimated initial mass of water for sample 8002EVS50R1 deviated by $0.2 \mathrm{mg}$, or $1.1 \%$ of the calculated mass. The estimated initial mass of water for sample 8003EVS50R2 deviated by $2.2 \mathrm{mg}$, or $10.1 \%$ of the calculated mass. While the specific source of this error was not identified, several possible explanations for individual sample error exist. The evaporation rate during the deceleration phase after exposure and during movement of the spray card from the rotary test fixture to the analytical balance was not accounted for due to undefined durations. These conditions would likely have resulted in increased evaporation rates prior to mass measurements and an underestimated initial mass when modeling the evaporation rate. Another possible

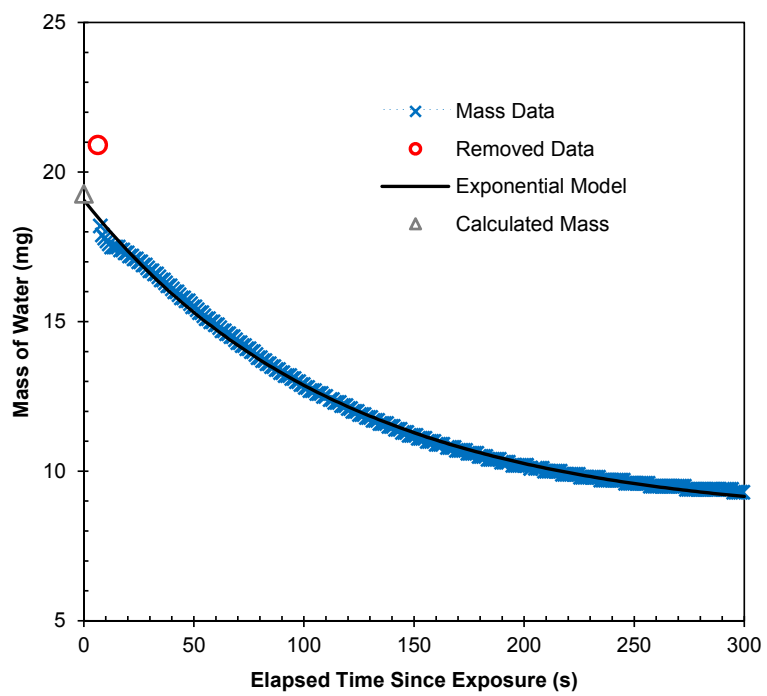

(a) Sample 8002EVS50R1

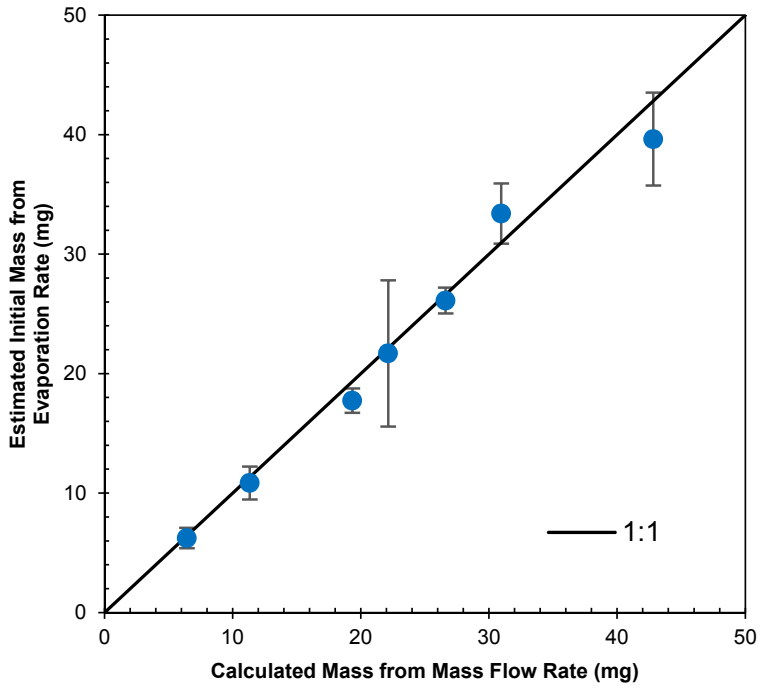

Figure 5. Comparison between calculated mass from mass flow rate and estimated initial mass from evaporation rate for all samples. Each point is the average of ten replications for a single nozzle, and the error bars represent \pm 1 standard deviation in calculated and estimated mass.

explanation is the error that resulted from using steady-state measurements to model an instantaneous process. Small variations in pressure over short time periods would result in an overestimated or underestimated calculated mass. The time delay between when pressure was recorded and the corresponding droplets striking the spray card is also a potential source of error under non-steady-state conditions.

The average estimated initial mass from the evaporation rate for a given nozzle tended to match the calculated mass from the mass flow rate (fig. 5). The largest deviations occurred at the largest two nozzle orifices (8006EVS and 8008EVS), and standard deviations between replications for a given nozzle were generally larger with larger nozzle orifices.

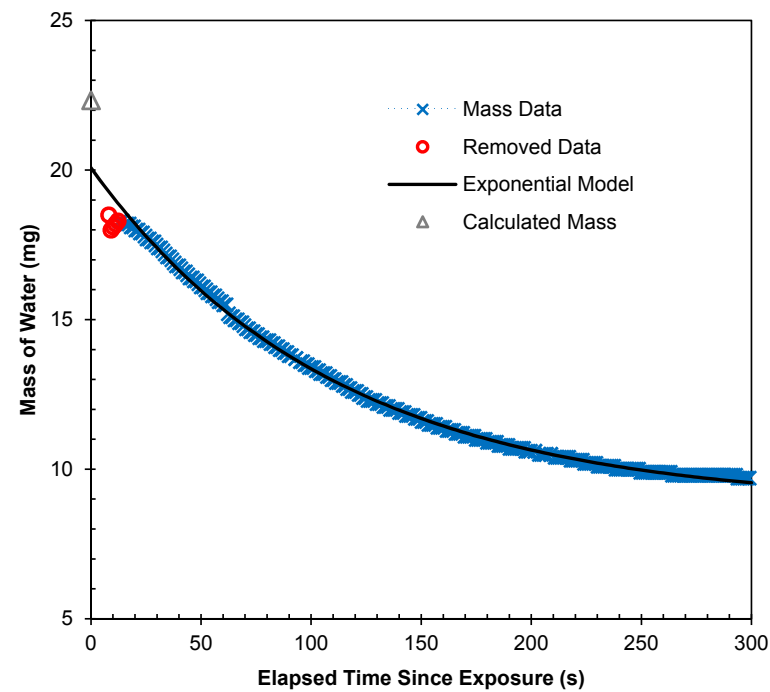

(b) Sample 8003EVS50R2

Figure 4. Example evaporation rate models and calculated mass from the mass flow rate for two spray treatments exhibiting (a) good and (b) poor alignment between the two methods. 
Table 2. Means and standard deviations (SD) of mass for mass flow (calculated) and evaporation rate (estimated) methods ( $p<0.05$ indicates a significant difference between the two sample means for a given nozzle model).

\begin{tabular}{ccccccc}
\hline & \multicolumn{2}{c}{ Calculated } & & \multicolumn{2}{c}{ Estimated } & \\
\cline { 2 - 3 } \cline { 5 - 6 } Nozzle & \multicolumn{2}{c}{ Mass } & & & Initial Mass & \\
\cline { 2 - 3 } Model & $(\mathrm{mg})$ & $(\mathrm{mg})$ & & $\begin{array}{c}\text { Mean } \\
(\mathrm{mg})\end{array}$ & $\begin{array}{c}\text { SD } \\
(\mathrm{mg})\end{array}$ & $\begin{array}{c}\text { p-Value } \\
(\alpha=0.05)\end{array}$ \\
\hline 8001EVS & 6.44 & 0.02 & & 6.23 & 0.86 & 0.467 \\
8002EVS & 11.33 & 0.05 & & 10.84 & 1.38 & 0.288 \\
8003EVS & 19.35 & 0.07 & & 17.73 & 1.02 & 0.001 \\
8004EVS & 22.14 & 0.12 & & 21.69 & 6.12 & 0.522 \\
8005EVS & 26.61 & 0.14 & & 26.11 & 1.08 & 0.161 \\
8006EVS & 30.96 & 0.22 & & 33.39 & 2.52 & 0.011 \\
8008EVS & 42.83 & 0.21 & & 39.63 & 3.88 & 0.029 \\
\hline
\end{tabular}

There was no significant difference between the calculated mass from the mass flow rate and the estimated initial mass from the evaporation rate for four of the seven nozzles (table 2). Nozzles 8003EVS, 8006EVS, and 8008EVS showed significantly different results between the two methods. Differences in standard deviations between the two methods for a given nozzle revealed how the experimental error differed between steady-state and instantaneous measurements. The standard deviation of calculated mass from the mass flow rate was more than an order of magnitude smaller than the standard deviation of initial mass from the evaporation rate for all nozzles. This was not surprising because the calculated mass from the mass flow rate represented a 15 to $120 \mathrm{~s}$ average, while the estimated initial mass from the evaporation rate nominally represented a $0.013 \mathrm{~s}$ sample (a 1,000 to 10,000 times shorter interval). Agreement in the average mass between the two methods can be explained by the low spatial and temporal variability in mass flow rate, i.e., the nozzle was providing a uniform steadystate output when operating at a constant pressure. An alternate explanation was that ten replications were sufficient for stabilizing the variability in mass flow rate.

\section{Sensitivity of Starting Point on Estimated INITIAL MASS FROM THE EVAPORATION RATE}

The impact of the starting point was considered because of the exponential trend in the evaporation data and its effect on extrapolating toward an initial mass value. Figure 6 shows the influence of starting time on the average magnitude of error between the calculated mass from the mass flow rate and the estimated mass from the evaporation rate. The average error varied between $2 \%$ and $8 \%$ when using the shortest possible delay. Nozzles 8001EVS and 8002EVS (fig. 7a) showed larger errors with increasing delay due to the small initial mass of water deposited on the spray card relative to the analytical balance resolution. An interesting trend was observed for nozzle 8003EVS (fig. 7b), where the error decreased as the starting point was delayed. This was due to an underestimated initial mass from the evaporation rate, which happened to increase and eventually exceed the calculated mass from the mass flow rate. Only the first starting point exhibited notable temporal variability due to the variable amount of time required to place the spray card on

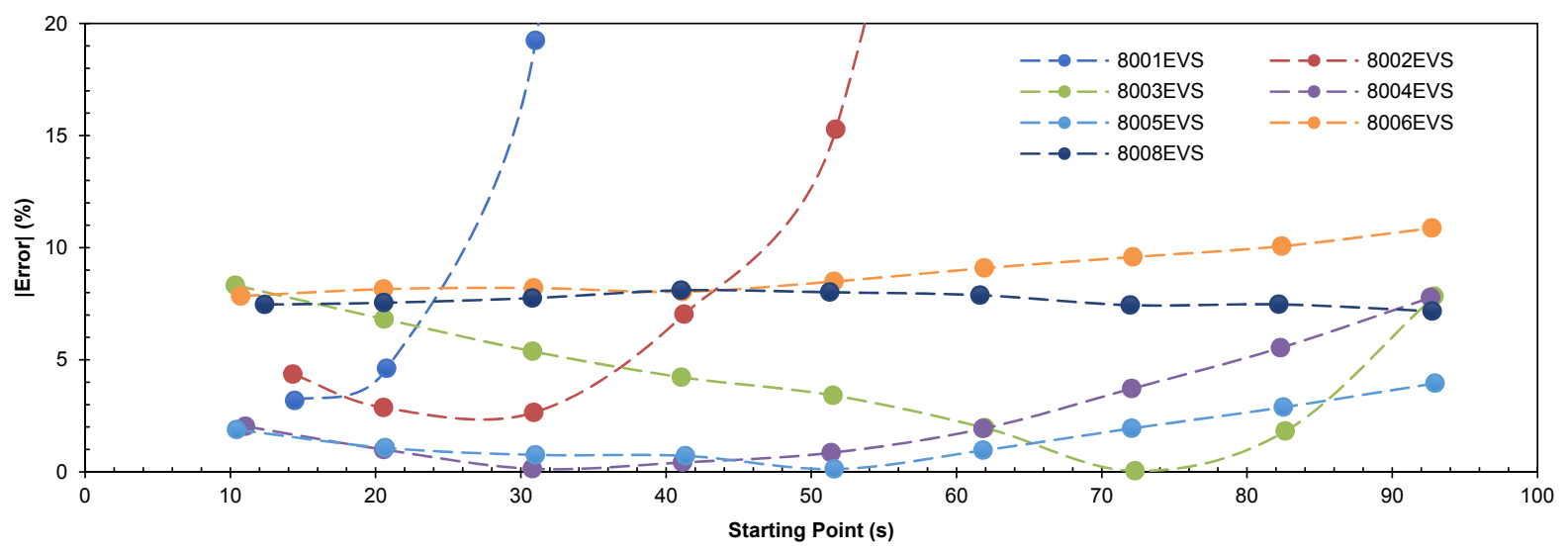

Figure 6. Average magnitude of error for varying average starting points for all nozzles tested. Starting times were varied in $10 \mathrm{~s}$ intervals to reveal the effect on the estimated initial mass of water. Each point is the average of ten samples for a single nozzle.

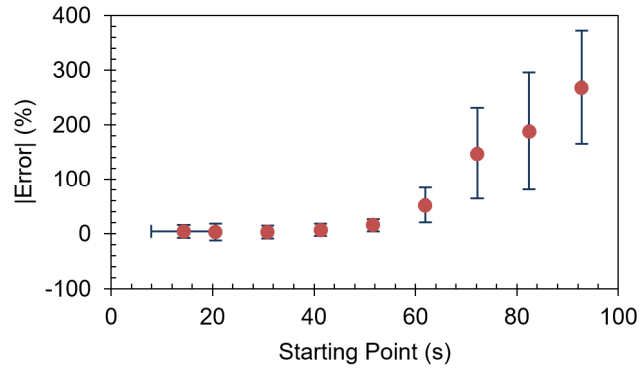

(a)

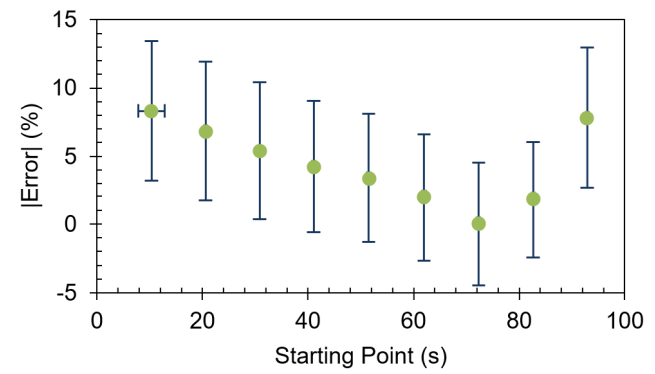

(b)

Figure 7. Average magnitude of error for varying average starting points for nozzles (a) 8002EVS and (b) 8003EVS. Each point is the average of ten replications for a single nozzle, and the error bars represent \pm 1 standard deviation in error and time. 
the analytical balance. The remaining starting points were all within $\pm 0.5 \mathrm{~s}$ of the average starting point as determined by the $1 \mathrm{~s}$ sampling interval.

Statistical t-tests $(\alpha=0.05)$ were performed and used to determine if a change in significance between the two methods occurred as the starting point changed (table 3 ). In general, increasing the delay in starting point resulted in more instances of significant differences between the two methods. All average estimated initial masses were significantly different from average calculated masses after $90 \mathrm{~s}$. This provides practical insight into the primary limitation of estimating the initial mass of water on a spray card using the evaporation rate, specifically that the exposed spray card must be placed on the analytical balance immediately after exposure

Table 3. Significance results between average calculated and estimated mass for delayed starting points $(0=$ no significant difference, $1=$ significant difference).

\begin{tabular}{cccccccccc}
\hline Nozzle & \multicolumn{10}{c}{ Average Starting Point (s) } \\
\cline { 2 - 10 } Model & $<20$ & 20 & 31 & 41 & 51 & 62 & 72 & 82 & 93 \\
\hline 8001EVS & 0 & 0 & 0 & 1 & 1 & 1 & 0 & 1 & 1 \\
8002EVS & 0 & 0 & 0 & 0 & 1 & 1 & 1 & 1 & 1 \\
8003EVS & 1 & 1 & 1 & 1 & 0 & 0 & 0 & 0 & 1 \\
8004EVS & 0 & 0 & 0 & 0 & 0 & 0 & 0 & 0 & 1 \\
8005EVS & 0 & 0 & 0 & 0 & 0 & 0 & 0 & 1 & 1 \\
8006EVS & 1 & 1 & 1 & 1 & 1 & 1 & 1 & 1 & 1 \\
8008EVS & 1 & 1 & 1 & 1 & 1 & 1 & 1 & 1 & 1 \\
\hline
\end{tabular}

when the mass flow rate is small and that sampling multiple spray cards (i.e., capturing the entire instantaneous spray distribution) from a single exposure would require multiple analytical balances. This limits the usefulness of estimating the initial mass on the spray card using the evaporation rate to laboratory experiments.

\section{COMPARING SPRAY CARd COVERAge TO LIQUID MASS ESTIMATES}

Average spray card coverage varied between $4.5 \%$ and $24.8 \%$ when operating the nozzles at $345 \mathrm{kPa}(50 \mathrm{psi})$ and $76 \mathrm{~cm}$ (30 in.) above a spray card traveling at $371 \mathrm{~cm} \mathrm{~s}^{-1}$. An example of the last replication from each nozzle model is shown in figure 8 . None of the spray cards exhibited saturation, which would have artificially lowered the percent coverage relative to the volume of water due to excessive overlap in droplets.

The relationship between spray card coverage and both calculated mass from the mass flow rate and estimated initial mass from the evaporation rate were highly linear $\left(\mathrm{R}^{2}=0.99\right.$ and 0.98 , respectively), and the slopes were nearly identical (fig. 9). A small offset was present when using spray card coverage to predict the estimated initial mass from the evaporation rate, which was deemed negligible due to the very low coverage percentages at which this offset would unde-

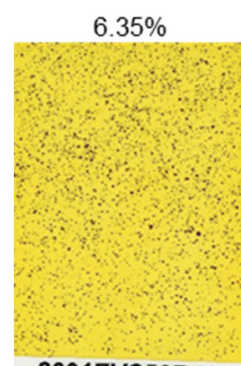

8001EVS50R10
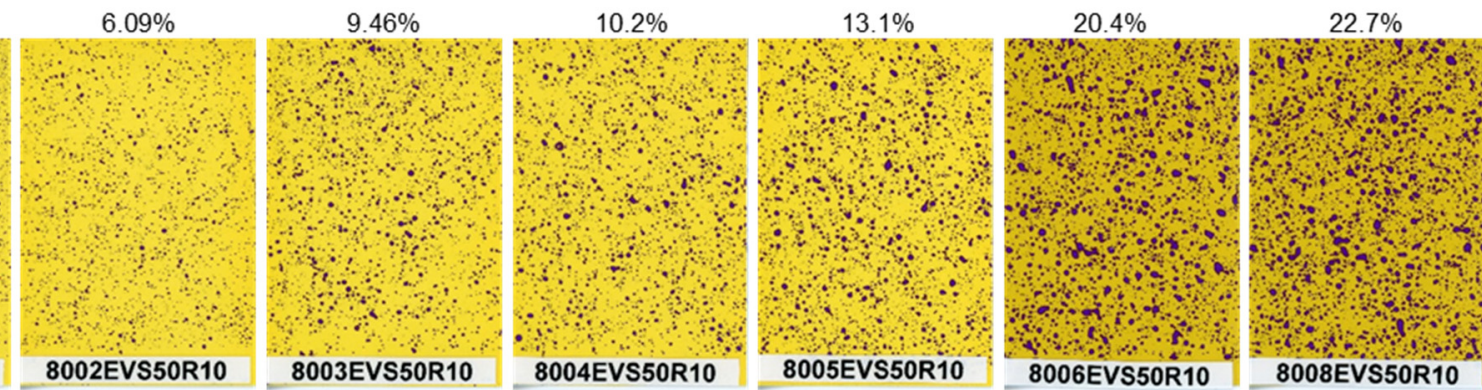

Figure 8. Sample exposed and labeled spray cards for each nozzle model with calculated coverage shown.

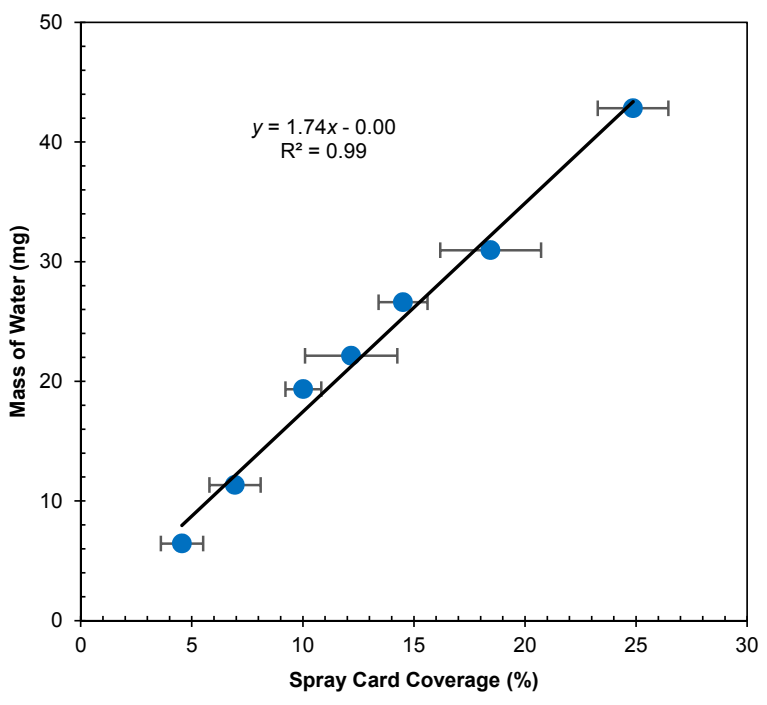

(a) Calculated mass vs. spray card coverage

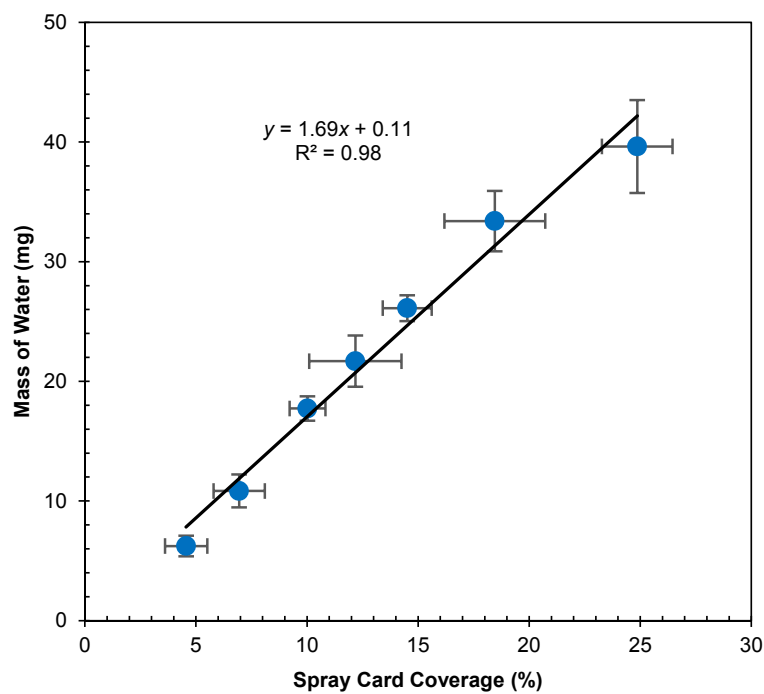

(b) Estimated mass vs. spray card coverage

Figure 9. Spray card coverage versus mass of water using the (a) mass flow and (b) evaporation rate methods. Each point is the average of ten replications for a single nozzle model, and the error bars are \pm 1 standard deviation in mass and percent coverage. 
sirably affect the mass prediction. Once again, the largest discrepancy between the steady-state and instantaneous methods was the variability in the calculated and estimated mass. Instantaneous sampling of the mass of water on a spray card introduced experimental uncertainty that was filtered out by collecting a sufficient number of replications.

Given that spray card coverage could accurately and precisely estimate the initial mass of water applied to a finite area, the choice between using spray card coverage or a mass estimate based on the evaporation rate depends on economic and practical considerations. WSP spray cards are cost-prohibitive when used in large quantities. However, they capture a snapshot of the as-applied volumetric or mass flow rate over a target area that can be post-processed at a later time. Estimated initial mass from the evaporation rate requires the spray card to be processed immediately. Measuring multiple spray cards simultaneously is cost-prohibitive due to the precise analytical balance needed to measure the small mass of water deposited. On the other hand, targets other than WSP spray cards could be used to spatially sample the spray pattern, which has the potential to lower the cost of repetitive laboratory sampling.

\section{Conclusion}

Several different methods were used to measure the asapplied mass of water on water-sensitive paper spray cards. The first method used steady-state analysis of the mass flow rate on a spray patternator table to calculate the mass of water deposited on the spray card. The second method used the mass of the exposed spray card over time to model the evaporation rate and estimate the initial mass of water at the time of exposure. Results showed that the average error between the methods ranged from $2 \%$ to $8 \%$. The mass flow method was viewed as more accurate because it sampled the nozzle spray over a longer period. However, varying field conditions, such as changes in wind velocity, require additional sensing and modeling if the mass flow rate is to be applied to field calculations of as-applied coverage rates. The evaporation rate method was viewed as less accurate and exhibited larger variability between replications. There are also practical limitations that make field-deployment of the evaporation rate method impractical. Despite this reduction in performance and deployment limitation, the evaporation rate method is still useful for laboratory testing, specifically when the nozzle flow rate is rapidly changing. Spray card coverage was compared to both methods and shown to be viable for estimating the mass of water on the spray card at the time of exposure. This improved on previous work by localizing the flow rate to the spray card rather than measuring the total flow rate at the nozzle. Ultimately, using the spray card coverage to estimate the mass or volume of water on the spray card is the most practical method for field work when as-applied measurements are needed.

The resulting methods will be an important step for validating as-applied sprayer performance in the field. The ability to measure the mass or volume of spray deposited to a known area is crucial for assessing modern variable-rate technology used in nozzle control systems. Measuring the local- ized as-applied application rate as opposed to the total volumetric flow rate for a single nozzle, as demonstrated by Sama et al. (2016), addresses a shortcoming of prior work that limited practical use under field conditions. Given an accurate model between spray card coverage and the mass or volume of water on the card, researchers will be able to conduct fieldscale studies validating spray application rates at high spatial resolutions. Future work should include increasing the complexity of the experiment to include overlapping nozzle patterns along with a wider range of nozzle types, droplet spectra, operating pressures, and environmental conditions to determine their effects on the accuracy of mass estimation.

\section{ACKNOWLEDGEMENTS}

This material is based on work supported by the USDA National Institute of Food and Agriculture under agreements 2017-67021-26250 and KY005038. Any opinions, findings, or conclusions expressed in this publication are those of the authors and do not necessarily reflect the views of the USDA. This is Publication No. 18-04-55 of the Kentucky Agricultural Experiment Station and is published with the approval of the director.

\section{REFERENCES}

Crowe, T. G., Downey, D., \& Giles, D. K. (2005). Digital device and technique for sensing distribution of spray deposition. Trans. ASAE, 48(6), 2085-2093. https://doi.org/10.13031/2013.20085

Fox, R. D., Derksen, R. C., Cooper, J. A., Krause, C. R., \& Ozkan, H. E. (2003). Visual and image system measurement of spray deposits using water-sensitive paper. Appl. Eng. Agric., 19(5), 549-552. https://doi.org/10.13031/2013.15315

Giles, D. K., \& Downey, D. (2003). Quality control verification and mapping for chemical application. Prec. Agric., 4(1), 103-124. https://doi.org/10.1007/s11119-010-9171-8

Hill, B. D., \& Inaba, D. J. (1989). Use of water-sensitive paper to monitor the deposition of aerially applied insecticides. J. Econ. Entomol., 82(3), 974-980. https://doi.org/10.1093/jee/82.3.974

Kesterson, M. A., Luck, J. D., \& Sama, M. P. (2015). Development and preliminary evaluation of a spray deposition sensing system for improving pesticide application. Sensors, 15(12), 3196531972. https://doi.org/10.3390/s151229898

Luck, J. D., Pitla, S. K., Zandonadi, R. S., Sama, M. P., \& Shearer, S. A. (2011). Estimating off-rate pesticide application errors resulting from agricultural sprayer turning movements. Prec. Agric., 12(4), 534-545. https://doi.org/10.1007/s11119-0109199-9

Luck, J. D., Schaardt, W. A., Sharda, A., \& Forney, S. H. (2016). Development and evaluation of an automated spray patternator using digital liquid level sensors. Appl. Eng. Agric., 32(1), 4752. https://doi.org/10.13031/aea.32.11381

Mangus, D. L., Sharda, A., Engelhardt, A., Flippo, D., Strasser, R., Luck, J. D., \& Griffin, T. (2017). Analyzing the nozzle spray fan pattern of an agricultural sprayer using pulse width modulation technology to generate an on-ground coverage map. Trans. ASABE, 60(2), 315-325. https://doi.org/10.13031/trans.11835

Salyani, M., \& Serdynski, J. (1990). Development of a sensor for spray deposition assessment. Trans. ASAE, 33(5), 1464-1468. https://doi.org/10.13031/2013.31494

Sama, M. P., Evans, J. T., Turner, A. P., \& Dasika. Saket, S. (2016). As-applied estimation of volumetric flow rate from a single sprayer nozzle series using water-sensitive spray cards. Trans. 
ASABE, 59(3), 861-869. https://doi.org/10.13031/trans.59.11538

Turner, C. R., \& Huntington, K. A. (1970). The use of a watersensitive dye for the detection and assessment of small spray droplets. J. Agric. Eng. Res., 15(4), 385-387. https://doi.org/10.1016/0021-8634(70)90099-5

Womac, A., Etheridge, R., Seibert, A., Hogan, D., \& Ray, S. (2001). Sprayer speed and venturi-nozzle effects on broadcast application uniformity. Trans. ASAE, 44(6), 1437-1444. https://doi.org/10.13031/2013.7011

Zhu, H., Salyani, M., \& Fox, R. D. (2011). A portable scanning system for evaluation of spray deposit distribution. Comput. Electron. Agric., 76(1), 38-43.

https://doi.org/10.1016/j.compag.2011.01.003 
Author

\begin{tabular}{|c|c|c|c|c|c|c|c|c|}
\hline \multirow{2}{*}{\begin{tabular}{|l|} 
First Name \\
Michael \\
\end{tabular}} & Middle & Surname & \multicolumn{3}{|l|}{ Role } & \multicolumn{2}{|l|}{ E-mail } & $\begin{array}{l}\text { Contact } \\
\text { author? }\end{array}$ \\
\hline & \multicolumn{2}{|r|}{ Sama } & \multicolumn{3}{|c|}{ Assistant Professor } & \multicolumn{2}{|c|}{ michael.sama@uky.edu } & Yes \\
\hline \multicolumn{9}{|l|}{ Affiliation } \\
\hline \multicolumn{3}{|l|}{ Organization } & \multicolumn{3}{|l|}{ Address } & & Country & URL \\
\hline \multicolumn{3}{|c|}{$\begin{array}{l}\text { Department of Biosystems and Agricul- } \\
\text { tural Engineering }\end{array}$} & \multicolumn{4}{|c|}{$\begin{array}{l}119 \text { C.E. Barnhart Building, University of Kentucky, Lexing- } \\
\text { ton, KY 40546; phone: } 859-218-4325\end{array}$} & USA & \\
\hline \multicolumn{9}{|c|}{ Author } \\
\hline First Name & Middle & Surname & \multicolumn{3}{|l|}{ Role } & \multicolumn{2}{|l|}{ E-mail } & $\begin{array}{l}\text { Contact } \\
\text { author? }\end{array}$ \\
\hline Austin & M. & Weiss & \multicolumn{3}{|c|}{ Graduate Research Assistant } & \multicolumn{2}{|c|}{ austin.weiss@uky.edu } & No \\
\hline \multicolumn{9}{|l|}{ Affiliation } \\
\hline \multicolumn{3}{|c|}{\begin{tabular}{|l|} 
Organization \\
\end{tabular}} & \multicolumn{3}{|c|}{ Address } & & Country & URL \\
\hline \multicolumn{3}{|c|}{$\begin{array}{l}\text { Department of Biosystems and Agricul- } \\
\text { tural Engineering }\end{array}$} & \multirow{2}{*}{\multicolumn{5}{|c|}{ University of Kentucky, Lexington, Kentucky }} & \\
\hline \multicolumn{4}{|c|}{ Author } & & & & & \\
\hline First Name & Middle & Surname & \multicolumn{3}{|l|}{ Role } & \multicolumn{2}{|l|}{ E-mail } & $\begin{array}{l}\text { Contact } \\
\text { author? }\end{array}$ \\
\hline Emma & $\mathrm{K}$. & Benedict & \multicolumn{3}{|c|}{ Undergraduate Research Assistant } & \multicolumn{2}{|c|}{ benedict.emma@yahoo.com } & No \\
\hline \multicolumn{9}{|l|}{ Affiliation } \\
\hline \multicolumn{3}{|c|}{\begin{tabular}{|l|} 
Organization \\
\end{tabular}} & \multicolumn{3}{|c|}{ Address } & & Country & URL \\
\hline \multicolumn{3}{|c|}{$\begin{array}{l}\text { Department of Biosystems and Agricul- } \\
\text { tural Engineering }\end{array}$} & \multirow{2}{*}{\multicolumn{5}{|c|}{ University of Kentucky, Lexington, Kentucky }} & \\
\hline Funding Info & 1ation & & & & & & & \\
\hline \begin{tabular}{|l|} 
Name of Fun \\
\end{tabular} & ng Organi & ation & & Func & ID (if & & or Award Num & \\
\hline USDA-NIFA & AFRI & & & & & & $-67021-26250$ & \\
\hline USDA Hatcl & & & & & & & 307000 & \\
\hline $\begin{array}{l}\text { Is your fundi } \\
\text { Is the contra } \\
\text { Does your co }\end{array}$ & $\begin{array}{l}\text { or grant } f \\
\text { start date a } \\
\text { ract requir }\end{array}$ & $\begin{array}{l}\text { om the U.S. gc } \\
\text { ter } 1 \text { January } \\
\text { making your } \mathrm{p}\end{array}$ & $\begin{array}{l}\text { ernment? yc } \\
16 \text { ? yes } \\
\text { lication pul }\end{array}$ & access after an e & rgo $\mathrm{p}$ & & & \\
\hline Publications & aff to Con & lete & & & & & & \\
\hline \begin{tabular}{|l} 
Start Date $(\mathrm{g}$ \\
\end{tabular} & erally one & ear from publ & ation date) & End D & e (blanl & ione) & & \\
\hline Copyright? & Year & ournal & & Volume, Issue & DOI & & Manuscript ID & \\
\hline yes & 2018 & ransactions o & he ASABE & $61(3) 887-895$ & 10.13 & rans. 12565 & MS12565 & \\
\hline
\end{tabular}

